\title{
Genome-wide map of quantified epigenetic changes during in vitro chondrogenic differentiation of primary human mesenchymal stem cells
}

Sarah R Herlofsen ${ }^{1 *}$, Jan Christian Bryne², Torill Høiby' ${ }^{1}$ Li Wang $^{3}$, Robbyn Issner ${ }^{3}$, Xiaolan Zhang ${ }^{3}$, Michael J Coyne ${ }^{3}$, Patrick Boyle ${ }^{3}$, Hongcang Gư ${ }^{3}$, Leonardo A Meza-Zepeda ${ }^{2}$, Philippe Collas ${ }^{4}$, Tarjei S Mikkelsen ${ }^{3,5}$ and Jan E Brinchmann ${ }^{1,4}$

\begin{abstract}
Background: For safe clinical application of engineered cartilage made from mesenchymal stem cells (MSCs), molecular mechanisms for chondrogenic differentiation must be known in detail. Changes in gene expression and extracellular matrix synthesis have been extensively studied, but the epigenomic modifications underlying these changes have not been described. To this end we performed whole-genome chromatin immunoprecipitation and deep sequencing to quantify six histone modifications, reduced representation bisulphite sequencing to quantify DNA methylation and mRNA microarrays to quantify gene expression before and after 7 days of chondrogenic differentiation of MSCs in an alginate scaffold. To add to the clinical relevance of our observations, the study is based on primary bone marrow-derived MSCs from four donors, allowing us to investigate inter-individual variations.
\end{abstract}

Results: We see two levels of relationship between epigenetic marking and gene expression. First, a large number of genes ontogenetically linked to MSC properties and the musculoskeletal system are epigenetically prepatterned by moderate changes in $\mathrm{H} 3 \mathrm{~K} 4 \mathrm{me} 3$ and $\mathrm{H} 3 \mathrm{~K} 9 \mathrm{ac}$ near transcription start sites. Most of these genes remain transcriptionally unaltered. Second, transcriptionally upregulated genes, more closely associated with chondrogenesis, are marked by H3K36me3 in gene bodies, highly increased H3K4me3 and H3K9ac on promoters and $5^{\prime}$ end of genes, and increased H3K27ac and H3K4me1 marking in at least one enhancer region per upregulated gene. Within the 7-day time frame, changes in promoter DNA methylation do not correlate significantly with changes in gene expression. Inter-donor variability analysis shows high level of similarity between the donors for this data set.

Conclusions: Histone modifications, rather than DNA methylation, provide the primary epigenetic control of early differentiation of MSCs towards the chondrogenic lineage.

\footnotetext{
*Correspondence: sarah.herlofsen@rr-research.no

'Institute of Immunology and Norwegian Center for Stem Cell Research, Oslo

University Hospital Rikshospitalet, Oslo 0424, Norway

Full list of author information is available at the end of the article
} 


\section{Background}

The best treatment of lesions of hyaline cartilage known to date is transplantation of in vitro expanded autologous chondrocytes [1]. However, as articular chondrocytes dedifferentiate during in vitro culture, the resulting tissue frequently consists of a mixture of hyaline and fibrous cartilage. A better strategy may be to produce an implant of hyaline cartilage by in vitro tissue engineering using mesenchymal stem cells (MSCs) and a biomaterial. Several approaches including a variety of scaffold systems have been used to induce chondrogenic differentiation of MSCs, but so far all have failed to produce perfect hyaline cartilage for clinical use $[1,2]$. To achieve this, it is important to understand the processes that regulate chondrogenic differentiation of MSCs.

Changes in epigenetic marks are known to be important regulatory factors in stem cell differentiation. Gene expression is correlated with the level of post-translational modifications of histone tails and DNA methylation of promoter regions. For embryonic stem cells (ESCs), lineage commitment is associated with repression of genes important for differentiation along other lineages [3-5]. This process frequently involves the polycomb-group mediated trimethylation of lysine 27 of histone 3 (H3K27me3) and DNA methylation of the promoter regions [6,7]. Transcriptionally active genes are marked by monoubiquitination of H2B followed by trimethylation of H3K4 (H3K4me3) and H3K9 acetylation (H3K9ac) on nucleosomes close to the transcription start site (TSS). Other histone modifications, including $\mathrm{H} 3 \mathrm{~K} 36 \mathrm{me} 3$, are associated with transcriptional elongation and occur throughout the body of transcribed genes. Additional transcriptional control is provided by cis-acting regulatory regions marked by H3K4me1 and H3K27ac $[4,5,8,9]$.

Less is known about the epigenetic control of gene expression during differentiation of multipotent stem cells. Analysis of genes regulating adipogenic differentiation of human MSCs revealed dynamic changes in histone marks reminiscent of those seen in ESCs [10] and modest changes in promoter DNA methylation [11]. Recent studies of differentiation of murine myogenic precursor lines and in vivo differentiation of murine hair follicle stem cells have focused on the importance of H3K27me3 $[12,13]$. Likewise, studies of human hematopoietic stem cells have focused on changes in genes concomitantly marked by H3K4me3 and H3K27me3 and changes in DNA methylation [6,14-16]. Except for a few studies of the DNA methylation status of some genes involved during in vitro chondrogenesis [17-19], nothing is known to date about epigenetic changes during chondrogenic differentiation of MSCs.

Embryological chondrogenesis is controlled by a complex interplay of growth- and transcription factors. Among the essential secreted factors are Tgf $\beta$ and Bmp proteins [20]. For in vitro differentiation of human MSCs a combination of TGF $\beta$ and BMP2 yields the most hyaline-like cartilage [21]. In vivo, the Sox9 transcription factor (TF) is essential through the entire process of chondrogenesis [22] but the co-activators LSox 5 and Sox 6 are also important for cartilage formation $[23,24]$. In vitro, transfection of SOX9, 5 and 6 together is sufficient to induce permanent cartilage in mesenchymal precursors [25]. Using TGF $\beta 1$ and BMP2 to induce chondrogenic differentiation in hMSCs in a selfgelling alginate scaffold system, we have recently shown that the differentiated cells upregulate the extracellular matrix (ECM) molecules typical of hyaline cartilage, and downregulate molecules typical of MSC functionality [26]. In this system, the SOX TFs are upregulated sufficiently to allow transcription of all essential ECM molecules. We reasoned that a system where availability of TFs is not rate limiting should be suitable to study the relationship between changes in gene expression and concomitant epigenetic changes. To this end we used whole-genome chromatin immunoprecipitation and deep sequencing (ChIP-seq) to quantify H3K4me3, H3K9ac, H327me3, H3K36me3, H3K4me1 and H3K27ac, and reduced representation bisulphite sequencing (RRBS) to quantify DNA methylation in hMSCs before and after 7 days of chondrogenic differentiation. To add to the clinical relevance of our observations, the study is based on primary bone marrowderived MSCs (BM-MSC) from four donors, which allowed us to also investigate the inter-individual variations in the dynamics of epigenetic marks. We find evidence of two levels of relationship between epigenetic marking and gene expression during chondrogenic differentiation of MSCs: a prepatterning level marked by moderate changes in H3K4me3 and H3K9ac near TSSs and no or little change in gene expression, and a level associated with transcriptional upregulation marked by increased H3K36me3 along the gene body and highly increased H3K4me3 and H3K9ac. The first level is generally associated with the musculoskeletal system and MSC functionality, while the second level is more specifically associated with chondrogenesis. Within the 7-day time frame, changes in promoter DNA methylation do not correlate significantly with changes in gene expression.

\section{Results}

Chondrogenic differentiation of hBM-MSCs in 3D scaffold

In order to create an implant which resembles articular cartilage of the knee, we embedded MSCs in alginate discs with the thickness of knee cartilage and exposed these constructs to a differentiation cocktail containing TGFB1, BMP2 and dexamethasone [26]. Evidence of chondrogenic differentiation is shown by upregulation of the chondrocyte marker gene COL2A1 and downregulation of the MSC marker gene CXCL12 (Figure 1A), by the 


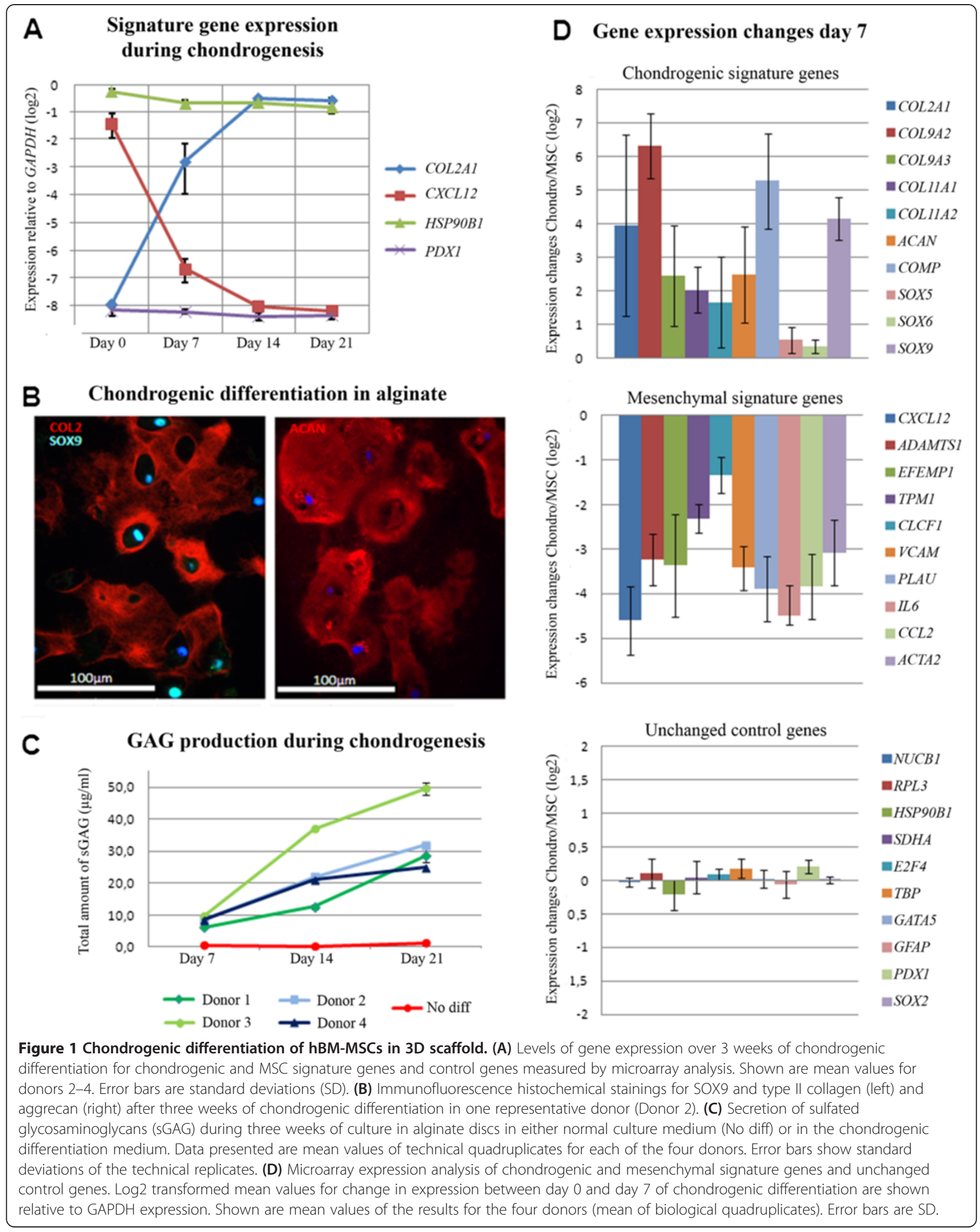


distribution of type II collagen and aggrecan throughout the extracellular space and SOX9 in the nuclei at three weeks of differentiation (Figure 1B), and by the increased synthesis of glycosaminoglycans (GAGs) during the differentiation period (Figure 1C). Details of gene expression and ECM composition using this model system are described in [26].

To first focus our epigenetic analyses on one set of genes typical of differentiated chondrocytes and another set typical of undifferentiated MSCs, we chose 10 canonical chondrogenic (COL2A1, COL9A2, COL9A3, COL11A1, COL11A2, ACAN, COMP, SOX5, SOX6 and SOX9) and mesenchymal (CXCL12, IL6, VCAM1, CCL2, PLAU, CLCF1, ADAMTS1, EFEMP1, ACTA2 and TPM1) signature genes (Figure 1D). The chondrogenic signature genes were selected because collagens II, IX and XI are the molecules required for synthesis of the hyaline cartilage collagen heterofibrils, which make up approximately $40 \%$ of the dry weight of hyaline cartilage. Aggrecan and COMP are two other essential components of hyaline ECM, while SOX9, 6 and 5 are essential transcription factors. The MSC signature genes were selected because they encode chemokines, cytokines and ECM degradation molecules important for the role played by MSCs in inflammation (CXCL12, IL6, VCAM1, CCL2, PLAU, CLCF1, ADAMTS1), or represent molecules involved in differentiation along other lineages (ACTA2, TPM1). All these genes are widely distributed throughout the genome, suggesting that if genes respond similarly to the differentiation process, this impact occurs genome-wide. We also included ten control genes representing highly (NUCB1, RPL3 and HSP90B1) and moderately (E2F4, TBP, SDHA) expressed housekeeping genes as well as non-expressed endodermal (GATA5, PDX1) and ectodermal (SOX2, GFAP) genes. The change in mRNA levels for these genes between day 0 and day 7 is shown in Figure 1D, and shows upregulation of the chondrogenic signature genes, downregulation of the MSC signature genes and no change for the control genes. Lists of all up- and downregulated genes in this differentiation system are found in Additional file 1 and Additional file 2.

\section{Histone modifications in promoters and gene bodies}

To describe the relationship between changes in gene expression and changes observed in the histone tails in nucleosomes, we quantified the presence of the transcriptionally permissive marks $\mathrm{H} 3 \mathrm{~K} 4 \mathrm{me} 3$ and $\mathrm{H} 3 \mathrm{~K} 9 \mathrm{ac}$ and the repressive mark H3K27me3 around the respective TSS in BM-MSCs from all four donors before and after 7 days of chondrogenic differentiation. We also quantified H3K36me3 throughout the length of the gene body. The genome-wide inter-donor variability of enrichment for the different histone marks during the differentiation period is presented in Figure $2 \mathrm{~A}$, and shows a remarkable similarity between donors for H3K4me3 $(R \geq$
0.95), H3K9ac $(R \geq 0.85)$ and H3K36me3 ( $R \geq 0.82)$. We found greater between-donor variability for H3K27me3 around the TSS, but this likely reflects the relatively low enrichment levels for this mark.

To extend the comparison to include both increases and decreases in histone marks, and to relate these changes to changes in gene expression, heat maps of genome-wide changes in facilitating promoter marks H3K4me3 and H3K9ac and restrictive promoter mark H4K27me3 are shown in Figure 2B, and a heat map of changes in H3K36me3 is shown in Figure 2C, in both cases directly comparable to changes in gene expression. As expected the maps representing the different promoter marks cluster together, with no apparent order between the donors. Upregulated H3K4me3 marks are seen to be closely related to promoters of genes with increased expression, while upregulated H3K9ac marks genes with increased expression, but also unchanged and perhaps even some downregulated genes. Upregulated H3K27me3 clusters with downregulated genes (Figure 2B). For H3K36me3 the relationship between enhanced histone mark and increased gene expression seems even stronger (Figure 2C).

Next we examined changes in histone modifications near upregulated chondrogenic signature genes, downregulated MSC genes and unchanged control genes. COL2A1 and CXCL12 are shown as representatives for the signature gene clusters (Figure 3). In MSCs, the promoter region of COL2A1 is marked by wide enrichment in H3K27me3 and no H3K4me3, which just shows a small peak in the first intron. This inactive state changed to a state marked by elevated H3K4me3 around the TSS. Interestingly, we did not observe a complete disappearance of H3K27me3. While this is reminiscent of the bivalent, or poised state described for non-transcribed, developmentally important genes in ESCs $[4,5,8]$, we note that at this time there was already a high level of transcription of the COL2A1 gene (Figure 1B). Thus, this apparent overlap is more likely to reflect that not all cells in the population express COL2A1 at this stage of differentiation. Promoter enrichment in H3K9ac and gene body occupancy by H3K36me3 are consistent with ongoing transcription (Figure 3A). In contrast, for the downregulated MSC marker gene CXCL12 we note the disappearance of H3K9ac and H3K36me3 and a restriction in H3K4me3 occupancy to the vicinity of the TSS. H3K27me3 increases significantly around the TSS but remains low at day 7 (Figure 3B). The persistently nontranscribed gene $P D X 1$ shows no activity marks and high levels of H3K27me3 throughout the gene and extending on both sides (Additional file 3A). As expected, the highly expressed housekeeping gene $H S P 90 B 1$ displays high levels of the activity marks H3K4me3, H3K9ac and H3K36me3 and no H3K27me3 (Additional file 3B). Analysis of the set of chondrogenic signature genes reveals a $>2$-fold increase 


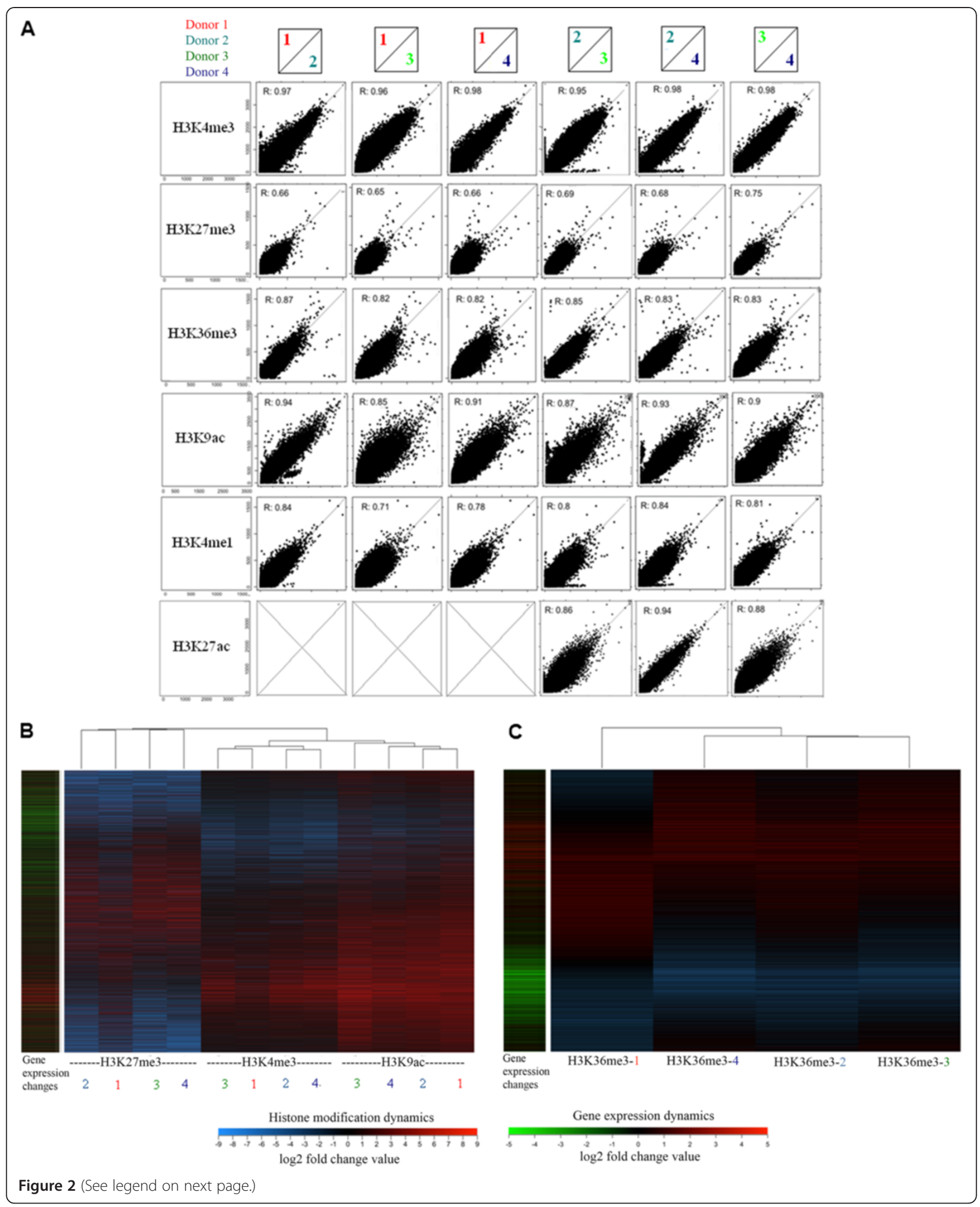


(See figure on previous page.)

Figure 2 (A) Correlation between all combinations of pairs of donors for enriched histone marks. Each dot plot is a comparison between the level of enrichment in a given histone mark after 7 days of differentiation from two donors. The values in each plot are the number of reads observed in genome-wide 500 bp regions with enrichment of the histone mark in that particular region in cells from at least one of the two donors. Included within each dot plot is the Spearman's rho correlation coefficient. Results for H3K27ac for donor 1 are not available due to a failed experiment. (B) Heat-maps of changes in the course of 7 days of chondrogenic differentiation in promoter marks $\mathrm{H} 3 \mathrm{~K} 27 \mathrm{me} 3$, $\mathrm{H} 3 \mathrm{~K} 4 \mathrm{me} 3$ and H3K9ac. Rows represent 500 bp regions where at least one experiment produced at least 200 aligned reads. The columns show changes in the indicated histone modifications and are sorted using hierarchical clustering with the clusters represented at the top of the figure. The rows are sorted using Principal Component Analysis where the order of the rows is defined by the first two principal components. Colour bars at the bottom of the figure show the colour analogue to the log2 fold change in histone marking or gene expression. Each column has 96013 rows.

in H3K4me3 and H3K9ac for most of the genes and in H3K36me3 in all of the genes (Figure 4A). H3K27me3 shows a $>2$-fold decrease during differentiation for four of the chondrogenic signature genes. All the downregulated MSC genes show reduced H3K4me3, H3K36me3 and H3K9ac on day 7 of differentiation, while the genes are still being expressed at moderate levels. Most of these genes also show a minor increase in H3K27me3 (Figure 4B). Control genes do not show any significant changes in any of the investigated marks (Figure 4C). Thus, for practically all signature genes examined, there is a close association between gene expression and detection of marks of active genes, and an inverse relationship between mRNA level and H3K27me3.

\section{Genome wide correlation between changes in H3K4me3 and changes in gene expression}

Based on the association observed between increased H3K4me3 and increased expression for the chondrogenic signature genes, we next investigated if increased H3K4me3 could be found for all genes that were transcriptionally upregulated. Of the 488 genes with increased mRNA levels, 90\% were associated with increased H3K4me3 around the TSS, with approximately 65\% showing a $>2$-fold increase (data not shown). We next determined if changes in $\mathrm{H} 3 \mathrm{~K} 4 \mathrm{me} 3$ were restricted to genes with concomitant changes in mRNA levels. While approximately 1000 genes were significantly either up- or downregulated upon chondrogenic differentiation, >2600 genes showed significant changes in H3K4me3 near the TSS (Additional file 4A). Gene ontology (GO)-term analysis of genes with increased H3K4me3 showed enrichment of functions linked to skeletal system development, ECM and chondrocyte differentiation. The functional terms for the genes with decreasing H3K4me3 were more general and associated with regulation of cytoskeleton, apoptosis, cell development or metabolic processes (Additional file 4B). Genome-wide, only $25 \%$ of the genes associated with a $>2$-fold change in H3K4me3 showed significant change in expression on day $7 \quad(\mathrm{p}<0.05)$ (Additional file 5A). Hardly any of these genes would change in expression over the next two weeks of differentiation, as the vast majority of genes that show change in expression during the first three weeks do so during the first week in this differentiation system. These results indicate that $\mathrm{H} 3 \mathrm{~K} 4 \mathrm{me} 3$ enrichment occurs during chondrogenic differentiation on genes that are ontologically close to cartilage and musculoskeletal systems, but that these genes are not transcriptionally activated at the $\geq 2$-fold level defined as significant in this study.

To determine if the magnitude of change in H3K4me3 might be a predictor for a change in gene expression we looked at the 500 regions with the greatest increase or decrease in H3K4me3 (Figure 5A). We found that $41 \%$ of the genes with the greatest increase, and $42 \%$ of the genes with the greatest decrease in H3K4me3 showed $>2$-fold transcriptional up- or downregulation, respectively (Additional file 4C), compared with $25 \%$ for all genes with changes in H3K4me3. GO-term analysis of the upregulated genes showed a closer correlation to ECM and cartilage (Figure 5B), while the downregulated genes showed properties associated with MSCs: differentiation to other lineages and association with angiogenesis and inflammation (Figure 5B). If the selection was limited further to include only the 100 TSS regions with the greatest level of up- or downregulation in $\mathrm{H} 3 \mathrm{~K} 4 \mathrm{me} 3$, $65 \%$ of the associated genes were found to be differentially expressed (data not shown). Of the genes associated with the greatest upregulation of H3K4me3, but with <2fold increase in mRNA level, many were either significantly upregulated $(\mathrm{p}<0.05)$ but $<2$-fold increased, were upregulated at a later time point during differentiation [26], showed activation of alternative promoters or were wrongly annotated (Additional file 6). In fact, only 8 of the 100 genes with the highest increase in H3K4me3 were transcriptionally unaffected. A similar conclusion could be drawn from the analysis of the genes that were most reduced in H3K4me3. Thus, the greatest changes in H3K4me3 were almost always associated with a change in gene expression.

\section{Correlation between combination of histone modifications and gene expression}

Most of the genes that were transcriptionally unchanged but with highly increased H3K4me3 had no increase in either H3K9ac or H3K36me3 or both. This suggests that lack of H3K9ac and/or H3K36me3 occupancy could explain why transcription of these genes did not change 


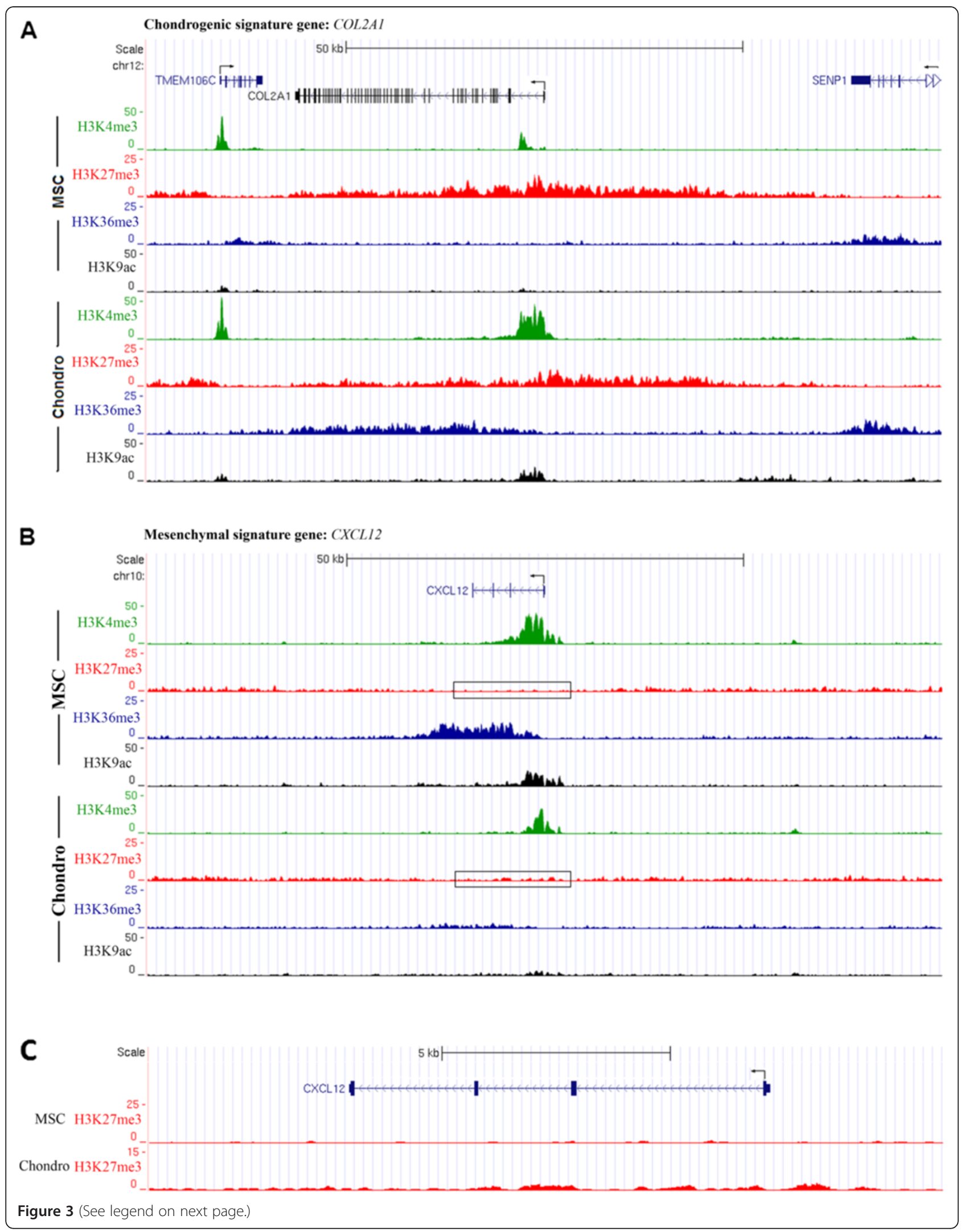


(See figure on previous page.)

Figure 3 Histone modification tracks of individual signature genes. (A) ChIP-seq signal tracks for histone modifications in a $100 \mathrm{~kb}$ window around the TSS of chondrogenic marker gene COL2A1. Exon-intron structures and coding strand direction are depicted on top. UCSC Genome Browser on Human Feb. 2009 (GRCh37/hg19) assembly. (B) ChlP-seq signal tracks for histone modifications in a $100 \mathrm{~kb}$ window around the TSS of MSC marker gene CXCL12. (C) ChIP-seq signal tracks for H3K27me3 in a higher resolution of MSC marker gene CXCL12.

despite their increased $\mathrm{H} 3 \mathrm{~K} 4 \mathrm{me} 3$, or that changes in H3K9ac and H3K36me3 did not occur because transcription did not change despite changes in H3K4me3 marking. Based on this observation, we determined the relationship between increased gene expression and the presence of all the gene-associated histone modifications, alone or in combination (Additional file 5). Not surprisingly, H3K4me3 and $\mathrm{H} 3 \mathrm{~K} 9 \mathrm{ac}$ were co-regulated around a large number of genes. However, the histone mark that most closely correlated with increased gene expression was H3K36me3. Of the 488 genes with increased mRNA levels, $94 \%$ had the H3K36me3 modification, $85 \%$ of these were numerically increased from day 0 to day 7 of differentiation, while $26 \%$ were $>2$-fold increased (Additional file 5 and data not shown). Taken together, this shows that highly increased levels of H3K4me3 and H3K9ac and

A Chondrogenic signature genes

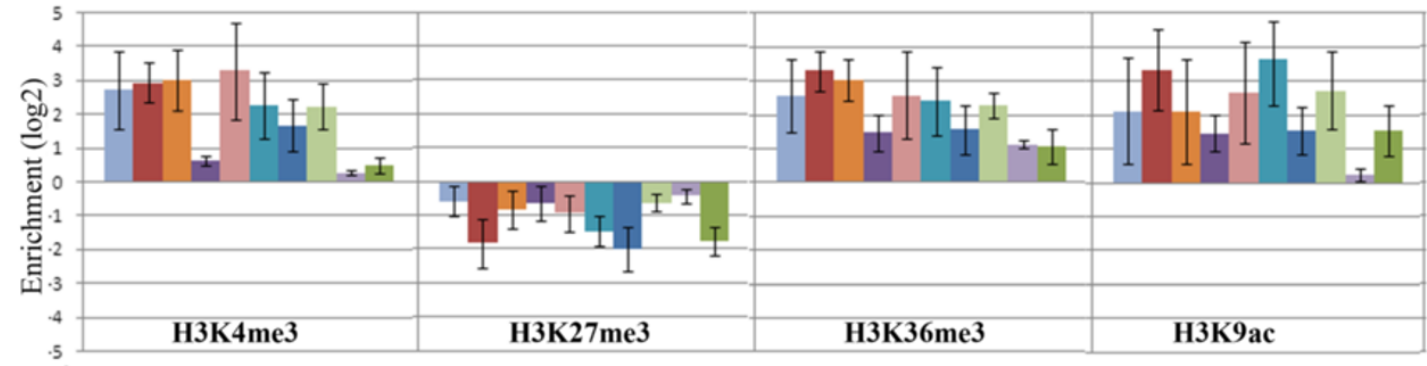

=COL2AI

- COL9A2

- COL9A3

¿COLIIAI

ECOLHA2

$=A C A N$

- СOMP

$=\operatorname{SOX} 5$

$=$ SoX 6

=sox 9

B Mesenchymal signature genes

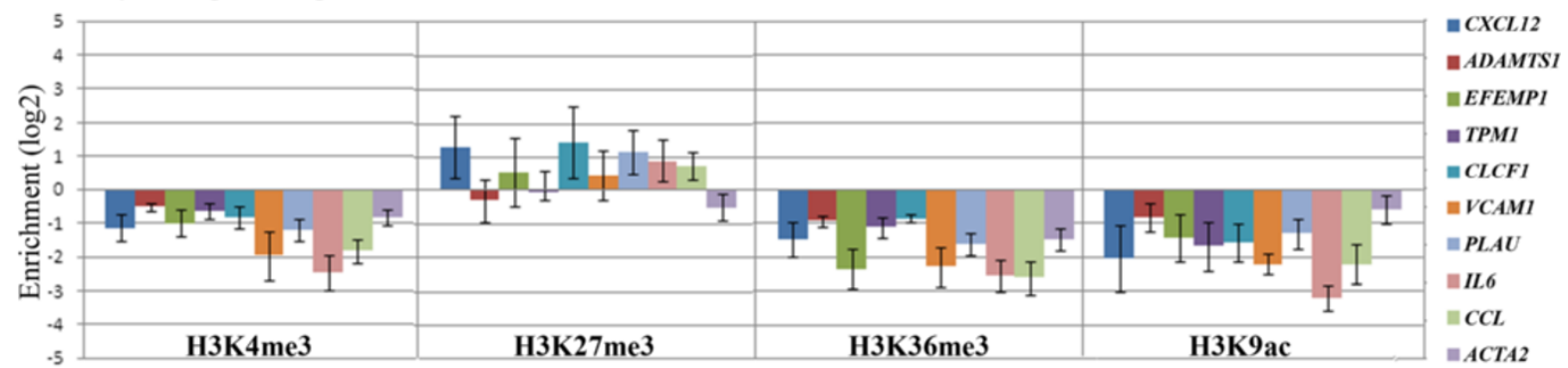

C Unchanged control genes

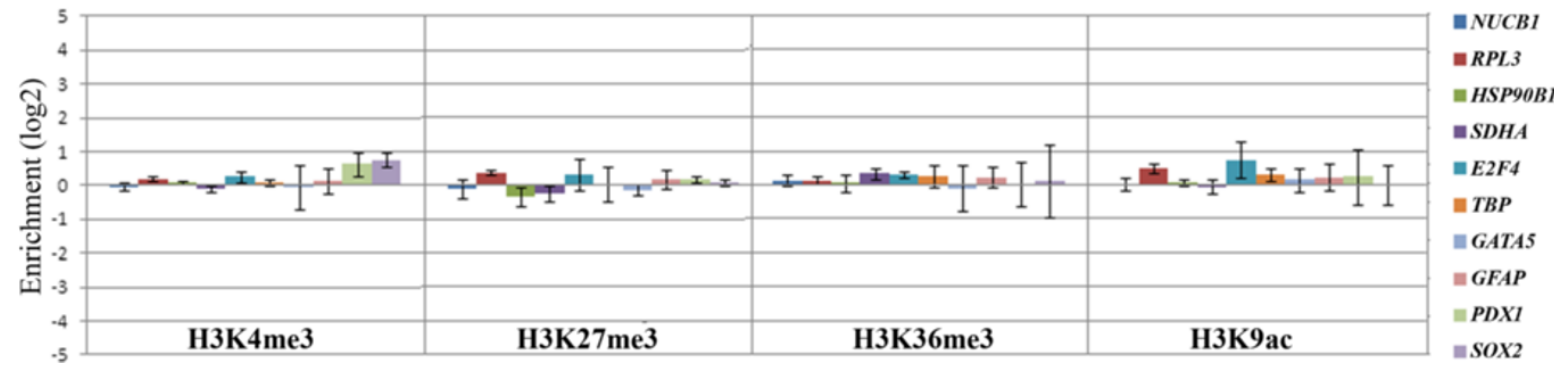

Figure 4 Profiling of epigenetic changes near signature genes. (A) Changes in histone marks for chondrogenic signature genes between day 0 and day 7 of chondrogenic differentiation. For H3K4me3, H3K27me3 and H3K9ac a 4 kb window around the TSS of all known transcripts was compared between the differentiation stages, while K36me3 reads were counted over the whole length of the longest known transcript. Shown is the log2 transformed histone enrichment ratio between differentiated cells and MSCs. Mean values of the results from the four donors (biological replicates) are shown. Error bars are SD. (B) Changes in histone marks for MSC signature genes between day 0 and day 7 of chondrogenic differentiation. Mean values of four donors with SD. (C) Changes in histone marks for unchanged control genes between day 0 and day 7 of chondrogenic differentiation. Mean values of four donors with SD. 
A

\section{K4me3- top 500 dynamic regions}



B

GO-Term analysis

top $500 \mathrm{H} 3 \mathrm{~K} 4 \mathrm{me} 3$ increase- expression change $>2$ fold (green)

\begin{tabular}{|l|l|l|l|}
\hline \multicolumn{1}{|c}{ GO-Term } & \multicolumn{1}{l}{ Pnalue } & \multicolumn{1}{l}{ Enrichment single term } & \multicolumn{1}{l|}{.Vnent cluster } \\
\hline proteinaceous extracellular matrix & $6,34 \mathrm{E}-13$ & 6,44 & 8,15 \\
\hline skeletal system development & $4,88 \mathrm{E}-13$ & 6,54 & 7,09 \\
\hline collagen & $5,77 \mathrm{E}-05$ & 14,14 & 4,54 \\
\hline cartilage development & $2,74 \mathrm{E}-05$ & 9,03 & 3,67 \\
\hline extracellular structure organization & 0,003 & 4,10 & 2,40 \\
\hline tissue homeostasis & $9,04 \mathrm{E}-04$ & 7,95 & 2,13 \\
\hline
\end{tabular}

top $500 \mathrm{H} 3 \mathrm{~K} 4 \mathrm{me} 3$ decrease- expression change $>2$ fold (blue)

\begin{tabular}{|l|l|l|l|} 
GO-Term & \multicolumn{1}{l}{ P-Value } & \multicolumn{1}{l}{ Enrichment single term } & \multicolumn{1}{l|}{ Enrichment cluster } \\
\hline $\begin{array}{l}\text { regulation of smooth muscle cell } \\
\text { proliferation }\end{array}$ & $2,62 \mathrm{E} 05$ & 11,70 & 3,86 \\
\hline regulation of cell growth & $3,18 \mathrm{E}-08$ & 6,34 & 3,86 \\
\hline blood vessel development & $6,69 \mathrm{E}-07$ & 5,02 & 3,62 \\
\hline regulation of cell adhesion & 0,009 & 3,93 & 3,59 \\
\hline regulation of chemotaxis & $4,43 \mathrm{E}-05$ & 14,88 & 3,55 \\
\hline $\begin{array}{l}\text { regulation of cytoskeleton } \\
\text { organization }\end{array}$ & $1,06 \mathrm{E}-05$ & 6,22 & 2,98 \\
\hline
\end{tabular}

Figure 5 (See legend on next page.) 
(See figure on previous page.)

Figure $\mathbf{5}$ Correlation between changes in gene expression and changes in promoter mark H3K4me3. (A) Association between change in gene expression and change in $\mathrm{H} 3 \mathrm{~K} 4 \mathrm{me} 3$ among the 500 regions which showed the highest increase or decrease in $\mathrm{H} 3 \mathrm{~K} 4 \mathrm{me} 3$ in promoter regions. (B) GO term analysis of genes within the top $500 \mathrm{H} 3 \mathrm{~K} 4 \mathrm{me} 3$ clusters which reached >2-fold expression change at day 7 of chondrogenic differentiation. DAVID cluster analysis was performed and one typical term per cluster is shown.

upregulated levels of $\mathrm{H} 3 \mathrm{~K} 36 \mathrm{me} 3$ are found near practically every transcriptionally upregulated gene in this differentiation system.

\section{The impact of cis-acting regulatory elements}

Regulation of gene transcription is controlled by factors acting in promoter regions as well as distant cis-regulatory elements. Different histone marks have been described to correlate with promoter and enhancer regions. Active enhancers are known to be marked by H3K4me1 and H3K27ac $[27,28]$. Heat maps for the associations between genes with changes in expression and H3K4me1 and H3K27ac marking within $50 \mathrm{~kb}$ of the TSS of these genes is shown in Figure 6A. A very clear association is seen between up- or down-regulation in gene expression and corresponding up- or down-regulation of the histone marks. Genome-wide, more than $70 \%$ of the upregulated genes were in the vicinity of upregulated enhancer regions, but since the number of regions with increased H3K4me1 or H3K $27 \mathrm{ac}$ was high, only approximately $15 \%$ of the genes within $50 \mathrm{~kb}$ of changes in these marks showed changes in mRNA expression (Additional file 7). This suggests that enhancer regions are important for most upregulated genes, but that the predictive power of a change in regulatory regions for the transcription of nearby genes is limited. A genome-wide list of genes which change in expression and show increase or decrease in one of these two regulatory marks in a $50 \mathrm{~kb}$ area is given as Additional file 8 (H3K4me1) and Additional file 9 (H3K27ac).

In order to identify potential chondrogenic enhancer regions, we investigated changes in these regulatory marks within $50 \mathrm{~kb}$ of the TSS of genes that changed transcriptionally during chondrogenic differentiation. For our signature genes, we found at least one site of $>2$ fold enrichment in both histone modifications near every chondrogenic signature gene, and at least one site with a significant $>2$ fold decrease of these marks near every MSC signature gene (Figure 6B). None of the unchanged control genes showed changes in $\mathrm{H} 3 \mathrm{~K} 4 \mathrm{me} 1$ or $\mathrm{H} 3 \mathrm{~K} 27 \mathrm{ac}$ (data not shown). The changes in H3K4me1 and $\mathrm{H} 3 \mathrm{~K} 27 \mathrm{ac}$ near the chondrogenic marker gene COL2A1 are shown in Figure 6C. We detected six areas with enrichment in both H3K4me1 and H3K27ac in the chondrogenically differentiated cells. Two of these could be identified as described and validated enhancer regions with binding sites for SOX9 [30-33]. The other four regions (Figure $6 \mathrm{C}$, marked in red) have not yet been described, and are likely to be new regulatory elements of importance for the regulation of COL $2 A 1$ expression.

\section{Transcription factor binding sites in cis-acting regulatory regions - Motif search}

The impact of changes in cis-acting regulatory elements on the regulation of gene expression most likely occurs through the binding of TFs. In order to identify TFs which may be involved in the regulation of chondrogenesis we performed a motif search in all areas with increase of H3K27ac during the differentiation process, using JASPAR, Transfac and Uniprobe databases. We found enrichment in motifs which could bind TFs belonging to several families (Figure 6D). The SRY family is especially important in the context of chondrogenesis, as it contains SOX5, 6 and 9, which are essential and sufficient to start the differentiation process $[23,34]$. The literature also contains evidence of involvement in chondrogenesis of members of all the other families with enriched binding motifs in these regions [35-38]. Interestingly, for most of these TF families binding motifs could be found also within the new regulatory areas close to the COL $2 A 1$ gene, further supporting their potential role in chondrogenic differentiation of MSCs (Figure 6D). Most significantly, new regions 1, 2 and 4 could be shown to contain 3,8 and 2 sequences identical to the SOX9 binding motif (AACAAT), respectively, while new region 3 contains no such sequences.

\section{Donor variability}

While the data comparing histone modifications genomewide between all four donors shows a low level of overall donor variability (Figure 2), some individual genes show variation between donors in mRNA levels and associated histone modifications. One example is COL $2 A 1$, where the gene expression on day 7 for donor 1 was considerably lower than for the other three donors. A similar observation was made for the upregulated gene $S O X 8$, but not for SOX9 (Figure 7A). When changes in histone modifications were examined for these genes, a much lower rate of change was observed for donor 1 for H3K4me3, K36me3 and H3K9ac for COL2A1 and SOX8, but not for SOX9 (Figure $7 \mathrm{~B}$ and $7 \mathrm{C}$ ), suggesting a correlation between gene expression and histone modification also at the single gene and individual donor level. Of the other genes identified which showed delayed transcriptional increase in 



\section{COL2A1 regulatory areas}

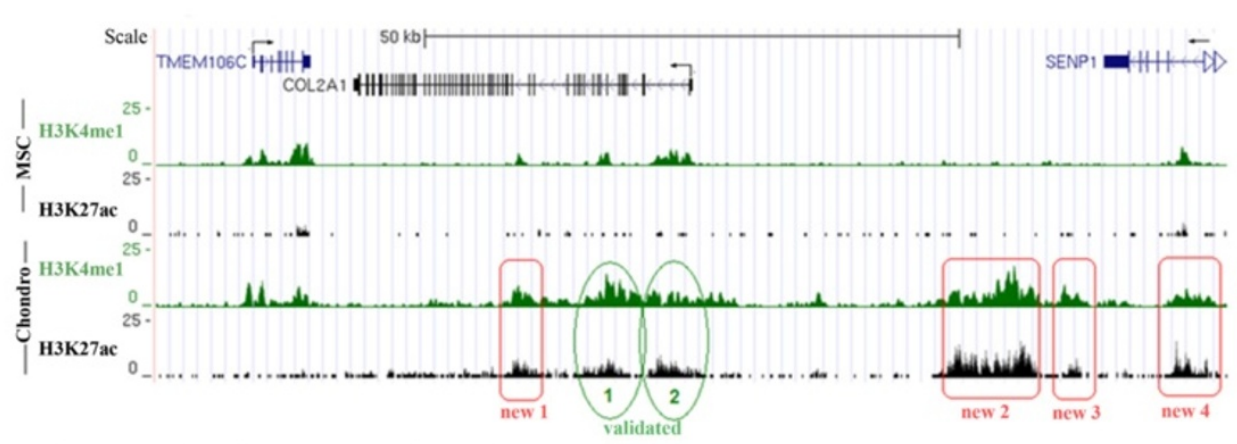

D Motif scanning in chondrocyte enriched K27ac areas

\begin{tabular}{|c|c|c|}
\hline $\begin{array}{l}\text { Enriched } \\
\text { TF-family }\end{array}$ & $\begin{array}{l}\text { Members involved } \\
\text { in chondrogenesis }\end{array}$ & $\begin{array}{c}\text { Example motif } \\
\text { (p-value, Fisher test) }\end{array}$ \\
\hline SRY & SOX5, 9 & $\because$ CAAT \\
\hline FOX & $\begin{array}{l}\text { FOXA2+3, } \\
\text { FOXC1 }+2 \text {, FOXEl }\end{array}$ & 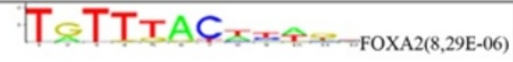 \\
\hline EBOX & ARNT, HIFIA, USF I & CACGTG ARNT (1,85E-04) \\
\hline SP/KLF & $\mathrm{SP} 1+3, \mathrm{MZF}-1$ & "CCC \\
\hline ETS & ETS-1, NFATC2 & -TTCC \\
\hline НОМЕОВОХ & $\begin{array}{l}\text { NKX3.2, API, } \\
\text { HOXA5, PAX }\end{array}$ & 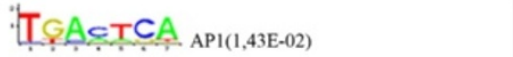 \\
\hline
\end{tabular}

Enriched motifs in $\mathrm{COL} 2 \mathrm{A1}$ regulatory areas

\begin{tabular}{|c|l|}
\hline Regulatory area & \multicolumn{1}{|c|}{ TF-family - Motif hits } \\
\hline New 1 & $\begin{array}{l}\text { SRY, EBOX, SP1/KLF, ETS, } \\
\text { HOMEOBOX }\end{array}$ \\
\hline Validated 1 & $\begin{array}{l}\text { SRY, FOX,SP1/KLF, ETS, } \\
\text { HOMEOBOX }\end{array}$ \\
\hline Validated 2 & $\begin{array}{l}\text { SRY, FOX, EBOX, SP1/KLF, } \\
\text { ETS,HOMEOBOX }\end{array}$ \\
\hline New2 & $\begin{array}{l}\text { SRY, FOX, EBOX, SP1/KLF, } \\
\text { ETS,HOMEOBOX }\end{array}$ \\
\hline New3 & FOX, EBOX, ETS \\
\hline New4 & $\begin{array}{l}\text { SRY, FOX, SP1/KLF, ETS, } \\
\text { HOMEOBOX }\end{array}$ \\
\hline
\end{tabular}

Figure 6 Finding potential cis-regulatory elements. (A) Heat maps of H3K4me1 and H3K27ac marks in regions located within 50 kb of the $5^{\prime}$ end of genes with significant changes in expression in the course of 7 days of chondrogenic differentiation in donors 2-4. Data for donor 1 are not available due to a failed experiment. Definition of rows, sorting of rows and clustering of columns as described in the Legend to Figure $2 \mathrm{~B}$. Each column has 262533 rows. (B) Profiles of the regulatory histone modification marks for selected chondrogenic and mesenchymal signature genes. Shown is the $500 \mathrm{bp}$ bin with the highest histone enrichment ratio for the indicated genes in a $50 \mathrm{~kb}$ area as mean value of three donors. Error bars are SD. (C) ChIP-seq signal tracks for H3K4me1 and H3K27ac in a $50 \mathrm{~kb}$ area on either side of the TSS of the COL2A1 gene. Validated (green) and potential new [29] regulatory areas are highlighted. (D) Left side: Motif scanning for transcription factor binding sites in regions enriched for H3K27ac in differentiated cells. Example motif shown from Jaspar database. The members of the TF families are TFs known to be involved in chondrogenesis which share similar binding motifs. Right side: Motif hits in regulatory areas around the COL2A1 gene. 


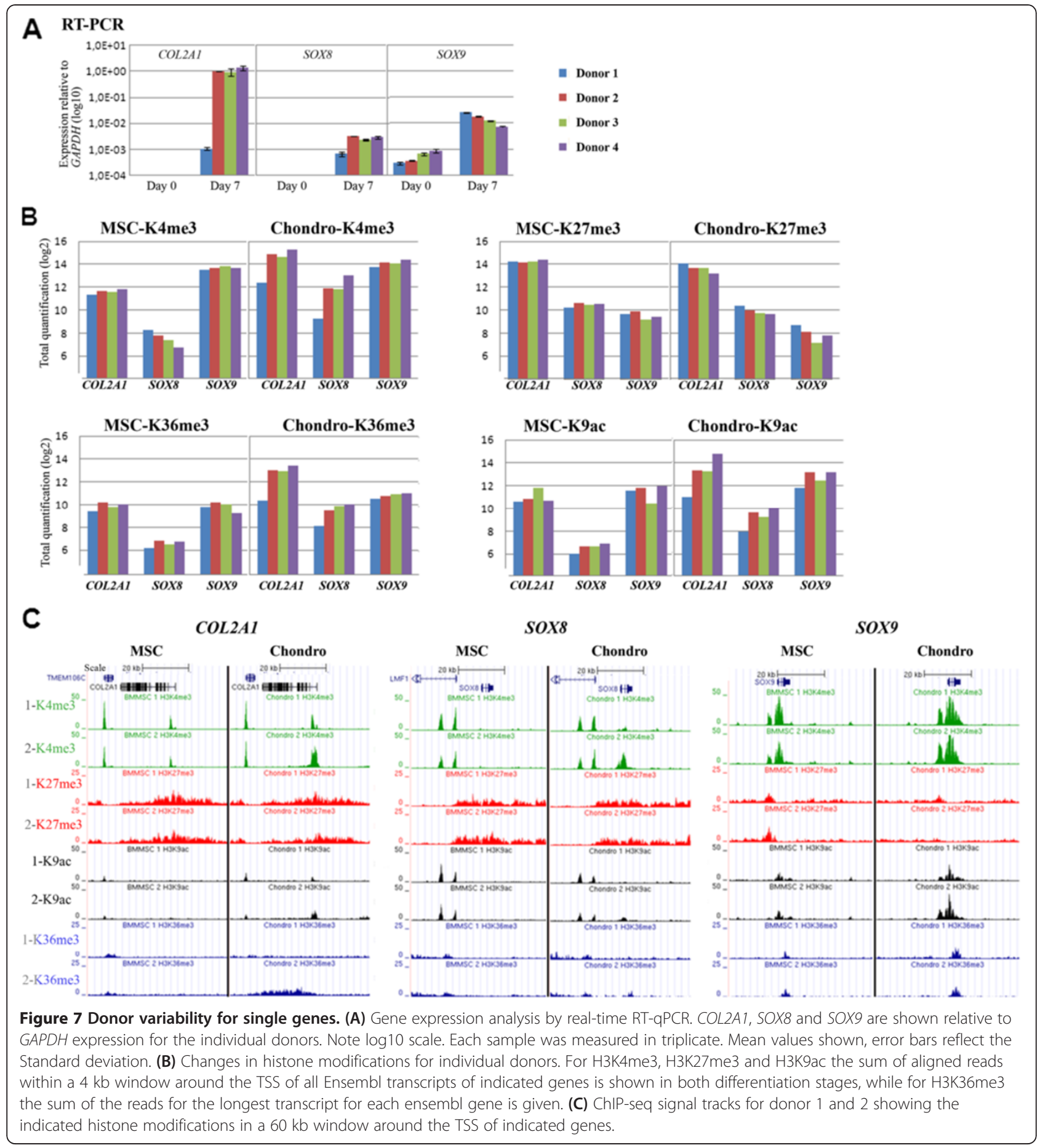

donor 1 compared to donors 2-4, the majority was found to have decreased upregulation of H3K4me3, K36me3 and H3K9ac for donor 1 compared with donors 2-4. Interestingly, there were no clear differences in these histone marks, H3K27me3 or DNA methylation at COL $2 A 1$ or $S O X 8$ in the undifferentiated cells, which suggests that these marks are not sufficient to predict the delayed differentiation response of donor 1.

\section{DNA methylation}

To determine if there is a relationship between DNA methylation and changes in gene expression before and after 7 days of chondrogenic differentiation, genomewide DNA methylation in CpG-rich regions was mapped using RRBS. More than $2 \times 10^{6}$ unique CpGs were observed with at least $10 \mathrm{X}$ coverage in most samples. The overall methylation patterns were highly similar 
between samples and followed expected patterns. CpGs in CpG-rich regions (including $\mathrm{CpG}$ islands) tended to be hypomethylated $(<10 \%$ median methylation across covered CpGs) while CpGs in CpG-poor regions tended to be hypermethylated ( $>50 \%$ median methylation; Additional file 10A). This relationship was preserved when the promoter regions were examined specifically. A highly significant correlation was found between the average methylation values for the MSC and the average methylation values for the chondrocytes in promoter regions $\left(\mathrm{r}^{2}=0.78\right)$, with the methylation states of the vast majority of promoters remaining unchanged [11]. For the MSC and chondrocyte signature genes, promoters were hypomethylated both before and after chondrogenesis, which suggests that DNA methylation is unlikely to play a major role in regulating these key genes during chondrogenesis. Genome-wide, only 37 promoters $(0.14 \%$ of those examined), including those of 9 microRNAs, showed a mean increase of at least $50 \%$ in methylation across the donors, and only 284 (1.1\%) showed more than a $25 \%$ increase. However, except for GAS6 (growth-arrest specific 6, five-fold downregulated, increased promoter methylation), these genes were generally expressed at low levels both before and after differentiation and no correlation to changes in the investigated histone marks could be detected. Moreover, at least 15 of the 37 genes that gained $>50 \%$ methylation across the donors were already hypermethylated in one of the donors prior to differentiation, which suggests that the observed promoter methylation events are not likely to be directly linked to regulation of chondrogenesis.

\section{Discussion}

\section{Chondrogenic differentiation opens up a new epigenetic landscape in MSCs}

In vitro tissue engineering of hyaline cartilage implants using MSCs and a biomaterial may well represent the best future treatment option for patients with lesions of articular cartilage. To be applicable to a wide range of patients the tissue engineering strategy should be robust, with little between-donor variability. Preferably, the differentiation process should be induced synchronously in all the cells used. A priori, this may be difficult to achieve: MSCs from different donors behave differently in cell expansion and differentiation cultures, and MSCs are known to be heterogenous both phenotypically and functionally $[39,40]$. In contrast, using the alginate disc differentiation procedure described here, hyaline ECM molecules are produced by the vast majority of cells in all donors tested so far [26] (Küchler AM and Brinchmann $\mathrm{JE}$, unpublished results). However, there is a delay between upregulation of mRNA and detection of ECM molecules, and ECM molecule synthesis does not seem to be synchronous. Against this background, we observe a remarkable similarity between the histone modifications induced after seven days of chondrogenic differentiation using bone marrow-derived MSCs from four donors. At this time, a new epigenetic landscape is opened up in these cells. Changes in the H3K4me3 and H3K9ac modifications occur near the TSS in thousands of genes, many of which are ontogenetically linked to skeletal system development, ECM, chondrocyte differentiation and MSC functionality. Although these modifications are known to be associated with initiation of transcription $[4,41]$, no significant change in mRNA levels is actually observed in the majority of these genes. With the level of change in gene expression set as significant in this study ( $\geq 2$-fold) it is possible that a small change in gene expression may accompany these changes in histone marks, or perhaps a greater change in a very small subset of cells. However, these changes are most reminiscent of the prepatterning of developmental gene expression by H3K4me3 recently observed in zebrafish before zygotic genome activation [42]. It is possible that every chondrogenic differentiation protocol would induce an epigenetic state that maintains activation potential of genes required both for the desired and also for related differentiation pathways [15]. It is also possible that certain components of the present differentiation cocktail, e. g. BMP2, may improve chondrogenic differentiation (Jakobsen RB, Østrup E, Mikkelsen TS and Brinchmann JE, unpublished observations) while at the same time setting an epigenetic stage also for bone differentiation.

\section{Close correlation between histone marks and gene expression}

Although many genes within the general domain of the musculoskeletal system show increased H3K4me3 following 7 days of chondrogenic differentiation, only the genes with the highest increase in H3K4me3 could be correlated with increased gene expression. The distribution of H3K4me3 and H3K9ac was, in many instances, very similar, suggesting co-occurrence on the same histone tails. H3K4me3 and H3K9ac may poise genes for transcription without transcription actually occurring. However, increased H3K4me3 and H3K9ac in promoter regions is, on its own, unlikely to explain the close correlation between highly increased H3K4me3 and $\mathrm{H} 3 \mathrm{~K} 9 \mathrm{ac}$ and increased transcriptional activity. Increase in the distribution of these modifications within the gene body may conceivably explain the increased rate of transcription, as H3K4me3 has also been suggested to stimulate transcriptional elongation [43]. However, the modification most closely correlated with increased transcription is H3K36me3. The combination of H3K4me3 with H3K36me3 is observed at practically every gene with increased mRNA level, and at few other genes. The 
following model may reconcile our results with current knowledge about the relationship between histone modifications and transcription. Trimethylation of H3K4 is regulated by several factors, including trithorax group proteins and cyclin-dependent kinase-9 (CDK9) of the positive transcription elongation factor-b complex ( $\mathrm{P}$ $\mathrm{TEFb})[43,44]$. The regulation of $\mathrm{H} 3 \mathrm{~K} 9 \mathrm{ac}$ is not well known, but its co-occurrence with H3K4me3 has been described [7,45], and the two modifications may have common chromatin readers [46,47]. These modifications frequently co-occur with RNA polymerase II [45]. However, transcriptional elongation does not occur in the absence of trimethylated H3K36 along the gene body. Methylation of H3K36 is performed by the methyltransferase Set2 and is, like H3K4 trimethylation, dependent on CDK9 $[44,48]$. CDK9 and Set2 are part of a large complex of proteins which is involved in the release of paused polymerase II [41]. With the factors responsible for trimethylation of H3K36 being part of the transcription elongation complex, it is uncertain at this time whether H3K36me3 is a prerequisite for, or a consequence of the passage of this complex along the gene body. In either case transcriptional elongation, heralded by $\mathrm{H} 3 \mathrm{~K} 36 \mathrm{me}$, is the most specific correlate of actively transcribed genes in the present data set. Further research will, hopefully, explain how transcriptional elongation is restricted to a set of genes with particular relevance for hyaline chondrogenesis in this differentiation model.

\section{Apparent co-occurrence of active and repressive marks}

Genes regulated both by H3K4me3 and H3K27me3 in the promoter region are called bivalent genes. ESCs are known to have a high proportion of bivalent genes, particularly genes responsible for specification along lineages $[4,5,8]$. These genes are not transcribed as long as differentiation is inhibited. On a cell population basis, we also observed what looks like bivalent genes, both among the upregulated chondrogenic signature genes and among the downregulated MSC signature genes. On day 7 of differentiation, transcription of all these genes was observed. We cannot rule out the possibility that there are genes among these that are actively transcribed in the presence of both H3K4me3 and H3K27me3 near the TSS. More likely, however, is an explanation based on non-synchronous changes in histone modifications and gene transcription between the different cells in a heterogeneous population. This would imply, for COL2A1, for instance, that one subset of MSCs lose H3K27me3 and gain H3K4me3 (and H3K36me3) at day 7. This subset is responsible for the observed increased level of COL2A1 mRNA, while another subset with retained H3K27me3 near the COL2A1 promoter does not support transcription. The level of COL2A1 mRNA increases further through days 14 and 21, which is consistent with subsequent loss of H3K27me3 and gain of active marks in cells that are still repressed at day 7 .

\section{Relationship between distal cis-regulatory elements and gene expression}

The genome-wide analysis of all $50 \mathrm{~kb}$ areas around TSS revealed a correlation between gene expression and changes in the regulatory histone marks H3K4me1 or H3K27ac. For the signature genes, every upregulated chondrogenic gene is associated with at least one upregulated enhancer region and every downregulated MSC-specific gene is associated with at least one downregulated enhancer region, whereas none of the control genes show any such change within the $50 \mathrm{~kb}$ region. For the COL $2 A 1$ marker gene, 4 new cisregulatory regions were discovered, all containing binding motifs for TFs essential for chondrogenesis. This strongly suggests that distal cis-regulatory regions impact importantly on the regulation of gene expression in this differentiation model. However, most of the histone modifications marking cis-regulatory regions occurred $>50 \mathrm{~kb}$ away from genes with changed expression, suggesting that the enhancers may be far removed from the target gene.

\section{Conclusion}

We have performed genome-wide quantitative epigenetic analysis on biological replicates of primary human MSCs undergoing chondrogenic differentiation in alginate disc scaffolds relevant for tissue engineering of hyaline cartilage. The differentiation cocktail and 3D culture induce changes in $\mathrm{H} 3 \mathrm{~K} 4 \mathrm{me} 3$ and $\mathrm{H} 3 \mathrm{~K} 9 \mathrm{ac}$ in genes associated with the musculoskeletal system, but mostly in the absence of changes in gene expression. Increased gene expression may be predicted by particularly high increase in H3K4me3 and by increase in H3K36me3. This implicates transcriptional elongation as the specificity conferring, rate limiting step in the differentiation process. Cis-regulatory activity marked by increasing $\mathrm{H} 3 \mathrm{~K} 27 \mathrm{ac}$ and H3K4me1 is involved in transcriptional regulation in the vast majority of genes with altered expression. Within the 7-day time frame, changes in promoter DNA methylation do not correlate significantly with changes in gene expression.

\section{Methods}

Culture and validation of MSCs

The study was approved by the Regional Committee for Medical Research Ethics, Southern Norway. Bone marrow was obtained from four healthy voluntary donors following informed, written consent. The MSCs were isolated and cultured as described in [26]. The cells were validated as MSCs by expression of CD105, CD73, CD90 
and CD44, and failure to express CD34, HLA- DR, CD45, CD14 and CD19. The multipotency of the MSCs was validated by differentiation to osteogenic and adipogenic lineages as previously described in [26].

\section{In vitro chondrogenic differentiation}

The chondrogenic differentiation system was described previously [26]. Briefly, MSCs were established in a selfgelling system containing PRONOVA-LVG alginate and calcium-alginate-particles to a final alginate concentration of $1 \%$ and a final cell concentration of $5 \times 10^{6}$ cells/ml. Chondrogenic differentiation was induced by $500 \mathrm{ng} / \mathrm{ml} \mathrm{BMP2,} 10 \mathrm{ng} / \mathrm{ml}$ TGFB1 and $0.1 \mu \mathrm{M}$ dexamethasone in serum free medium containing supplements as described [26].

\section{Validation of extracellular matrix synthesis}

Fluorescence immunohistochemistry was performed as described [26] with reagents as specified in Additional file 11 . The supernatants from disc cultures were analyzed for sulfated glycosaminoglycan content in technical quadruplicates for each donor using the Blyscan ${ }^{\mathrm{TM}}$ kit (Biocolor Ltd).

\section{RNA preparation and expression analysis}

Total RNA was prepared using TRIzol (Invitrogen). Depolymerisation of the alginate discs to obtain single cells for RNA isolation was performed by enzymatic digestion using G-Lyase (kindly provided by professor Gudmund Skjåk-Bræk) as described in [26]. RT-qPCR was performed using TaqMan arrays (Applied Biosystems) and normalized to GAPDH expression. Results are presented as mean plus standard deviation of technical triplicates. Microarray assays were performed in uniplicates per donor and differentiation state using the Human-6 v3 Expression Beadchips (Illumina), and the analysis was performed using J-express 2009 [49].

\section{ChIP-seq}

After degelling, cells were fixed in 1\% formaldehyd for $10 \mathrm{~min}$ at $37^{\circ} \mathrm{C}$ and stored at $-80^{\circ} \mathrm{C}$. ChIP and Illumina sequencing library construction was performed as described in $[3,4]$.

\section{Sequence analysis}

Tracks were uploaded in a UCSC Genome Browser, using unique reads extended to $200 \mathrm{bp}$. Experiments were normalized by enforcing equal read counts. $500 \mathrm{bp}$ bins were generated, and the coverage in each bin was calculated for both chip and control. For each bin, a fold change value and a poisson $\mathrm{p}$-value was generated. Pvalues were FDR corrected. The read counts from all experiments were quantile normalized. Bins with a log2 fold change $>0.2$ or $<-0.2$ in at least three of the four replicates were defined as having an increased or decreased signal, respectively. For quantification of H3K27me3, H3K4me3, and H3K9ac the sum of aligned reads within $2 \mathrm{~kb}$ on both sides of the TSS for each gene was calculated. This was performed for all biological replicates for both MSCs and differentiated cells, and a mean for each cell population was calculated. For H3K36me3, with known functionality throughout the entire gene [50], the longest transcript for each Ensembl gene was selected. The total number of aligned reads within this transcript was then calculated for all biological replicates in both cell populations, and a mean for each population was calculated. For the profiling of $\mathrm{H} 3 \mathrm{~K} 4 \mathrm{me} 1$ and H3K27ac signals the highest ratio of bins associated to a single gene was calculated.

\section{Gene association}

For promoter marks, Ensembl transcripts were used to identify transcripts with a $5^{\prime}$ end within $2 \mathrm{~kb}$ of bins. The transcript with the closest $5^{\prime}$ end was selected. For enhancer marks the association was made to the most differentially expressed gene within $50 \mathrm{~kb}$. Microarray expression data were integrated using refseq IDs.

\section{Motif enrichment analysis}

For each histone mark, the top 5000 increasing and decreasing bins were selected. Bins next to each other were merged. The regions were scanned with motifs from Jaspar, Transfac and Uniprobe with a score threshold of $80 \%$. Fisher test was used to compare the number of sequences with at least one hit and the number of sequences with no hits between the two sets. Wilcox test was used to compare the rank of total number of hits between the two sets. Motifs with a p-value $<0.05$ from both tests were defined as significant.

\section{DNA methylation}

RRBS was performed as previously described [51]. To analyze potential changes in promoter DNA methylation during chondrogenesis we examined 26,003 distinct TSSs annotated on the UCSC Genome Browser (derived from the gh19 refFlat database). For each sample, we assigned a methylation value to each TSS for which we had at least 5 distinct $\mathrm{CpGs}$ with at least $5 \mathrm{X}$ coverage each within $-1,000 \mathrm{bp}$ to $+1,500$ bp relative to the TSS. The methylation value for each such TSS was taken to be the median methylation value of all of the CpGs within this region with at least $5 \mathrm{X}$ coverage, using at least three of the four donors in each state.

\section{Sequences and data access}

All ChIP-Seq and RRBS data have been deposited in public databases and can be accessed from the NIH Roadmap Project on Epigenomics website: http://www. 
roadmapepigenomics.org/ and in the NCBI GEO database under accession GSE19465.

\section{Additional files}

Additional file 1: Genes with up-regulated expression during chondrogenic differentiation. Shown is the microarray expression data for all four donors, with mean values for chondrogenic and mesenchymal cells and the enrichment ratio as $\log 2$ transformed values.

Additional file 2: Genes with down-regulated expression during chondrogenic differentiation. Shown is the microarray expression data for all four donors, with mean values for chondrogenic and mesenchymal cells and the enrichment ratio as $\log 2$ transformed values.

Additional file 3: Histone modification tracks of non-changed control genes. ChIP-seq signal tracks for histone modifications in a $100 \mathrm{~kb}$ window around the TSS of non-expressed control gene PDX1. Exon-intron structures and coding strand direction are depicted on top. UCSC Genome Browser on Human Feb. 2009 (GRCh37/hg19) assembly. (A)ChIP-seq signal tracks for histone modifications in a $100 \mathrm{~kb}$ window around the TSS of highly expressed control gene HSP9OBT.

Additional file 4: Correlation between changes in gene expression and changes in promoter mark H3K4me3. (A) Genome-wide association between changes in gene expression $(>2$-fold, $p<0.05)$ and changes in H3K4me3 ( $>2$-fold in at least 3 out of 4 donors) during 7 days of differentiation. (B) GO term analysis of all genes where H3K4me3 changed $>2$-fold in 3 out of 4 donors. A cluster analysis using DAVID was performed, and one typical term per cluster is shown. (C) Counts of genes in the different expression clusters for all dynamic H3K4me3 regions and the 500 regions which changed the most in H3K4me3 (up or down) during one week of chondrogenesis. (D) GO term analysis for genes within the top 500 regions which increased or decreased in H3K4me3, but failed to reach a $>2$-fold expression change. DAVID analysis was performed, and one typical term per cluster is shown.

Additional file 5: Correlation between presence or absence of gene expression and change in promoter associated histone modifications. (A) Correlation between changes in histone marks and presence or absence of changes in gene expression. Shown is the percentage of genes clustered according to gene expression within groups characterized by single or combined significant changes in histone modifications. Expression cluster: $\uparrow:>2$ fold upregulated, $\downarrow:>2$ fold downregulated, $\leftrightarrow:<2$ fold changed. Numbers are mean values for all four donors. (B) Table showing the total number of genes associated to the indicated dynamic regions and expression clusters. Numbers are mean values of all four donors.

Additional file 6: Analysis of genes within the Top 500 with increased H3K4me3 which did not meet significance criteriae for increased gene expression. (A) Categories of genes which failed to reach the significance criteriae $(>2$-fold increase, $p<0.05)$ for increased gene expression. (B) Details of gene expression analysis [52] and epigenetic profile (bottom) for SOX5 as an example of a chondrogenic signature gene with <2-fold, but significantly changed mRNA expression. (C) ChIP-seq signal tracks for histone modifications of the SOX5 gene. Exon-intron structures and coding strand direction are depicted on top. UCSC Genome Browser. (D) ChIP-seq signal tracks of KLHL5 as an example for genes within the top 500 genes with increased H3K4me3 due to activation of an alternative promoter, without change in the level of mRNA expression. (E) Example of wrong gene annotation. ChIP-seq signal tracks for histone modifications and data for changes in gene expression for RAB4B and MIA.

Additional file 7: Correlation between gene expression and changes in regulatory histone marks. (A) Correlation between changes in histone marks and presence or absence of changes in gene expression. Shown is the percentage of genes clustered according to gene expression within groups characterized by single cis-regulatory histone marks, Expression cluster: $\uparrow:>2$ fold upregulated, $\downarrow$ : $>2$ fold downregulated, $\leftrightarrow:<2$ fold changed. (B) Statistics of correlation between changes in histone marks and gene expression. Shown is the percentage of genes in different expression clusters associated to the indicated >2fold changed histone modifications and their indicated combination. Table showing the total number of genes associated to the indicated dynamic regions and expression clusters. Numbers are mean values of all four donors.

Additional file 8: Genes which have a change in expression combined with a change in the level of H3K4me1 with in $50 \mathrm{~kb}$ of the TSS. Shown is gene identification and localization with expression values followed by the values for H3K4me1 marking where this is significantly changed in nearby $500 \mathrm{bp}$ bins. In addition the gene expression for the associated genes is given as mean values for the three investigated donors.

Additional file 9: Genes which have a change in expression combined with a change in the level of H3K27Ac with in $50 \mathrm{~kb}$ of the TSS. Shown is gene identification and localization with expression values followed by the values for H3K27Ac marking where this is significantly changed in nearby $500 \mathrm{bp}$ bins. In addition the gene expression for the associated genes is given as mean values for the three investigated donors.

Additional file 10: DNA-Methylation levels during chondrogenesis. (A) Distribution of methylation levels for individual CpGs with at least 10X coverage in each sample, as a function of local CpG density (+/50 bp). Shown is data of one typical donor. (B) Comparison of the average MSC and Chondro methylation value for 13,210 distinct transcription start sites (TSSs) annotated on the UCSC Genome Browser.

Additional file 11: Primers used in real-time RT-PCR and antibodies used in immunohistochemistry.

\section{Abbreviations}

MSC: Mesenchymal stem cell; BM-MSC: Human bone marrow-derived mesenchymal stem cells; ESC: Embryonal stem cell; ECM: Extracellular matrix; TSS: Transcriptional start site; TF: Transcription factor; ChIP-seq: Chromatin immunoprecipitation and deep sequencing; RRBS: Reduced representation bisulphite sequencing; GAG: Glycosaminoglycan; CDK9: Cyclin-dependent kinase-9; P-TEFb: Positive transcription elongation factor-b complex.

\section{Competing interest}

The authors declare that none of them have competing interest of any kind.

\section{Authors' contribution}

SRH, TSM and JEB conceived of the study and its design, SRH and TH performed cell work and library preparation, JCB performed the biostatistical analyses, SRH, JCB, LAMZ, PC, TSM and JEB analysed the data, LW, RI, XZ, MJC, PB and HG made the library and performed the sequencing, SRH and JEB wrote the manuscript with substantial input from JCB, TH, PC and TSM and JEB supervised the study. All authors contributed to and approved the final manuscript for publication.

\section{Authors' information}

Reprint author: Jan E. Brinchmann MD, PhD

Institute of Immunology, Oslo University Hospital Rikshospitalet, PO Box 4950 Nydalen, 0424 Oslo, Norway

Telephone: +4722 840489

Fax: +4722851058

E-mail: jan.brinchmann@rr-research.no

\section{Acknowledgments}

This work was supported by a grant from South-Eastern Norway Regional Health Authority, Storforsk and Stamceller grants from the Research Council of Norway and Gidske og Peter Jacob Sørensens Foundation for the Promotion of Science. Data generation was supported by the NIH Roadmap Epigenomics Program (grant U01ES017155 to Bradley E. Bernstein) and performed by the NIH Reference Epigenome Mapping Center at the Broad Institute. We thank Leif Lindeman for introduction to the ChIP assay and Axel Küchler for performing the immunohistochemical stainings shown in Figure 1B. We acknowledge Professor Gudmund Skjåk-Bræk, Norwegian University of Science and Technology, Trondheim, Norway for providing us 
with G-Lyase. We thank Charles B. Epstein, Tim Fennell and Noam Shoresh, Broad Institute, Cambridge, MA, for epigenomics pipeline support.

\begin{abstract}
Author details
'Institute of Immunology and Norwegian Center for Stem Cell Research, Oslo University Hospital Rikshospitalet, Oslo 0424, Norway. ${ }^{2}$ Department of Tumor Biology, Institute for Cancer Research, Oslo University Hospital Radiumhospitalet, Oslo 0424, Norway. ${ }^{3}$ Broad Institute of MIT and Harvard, Massachusetts 02142, USA. ${ }^{4}$ Institute of Basic Medical Sciences, Department of Biochemistry, University of Oslo, Oslo0317, Norway. ${ }^{5}$ Harvard Stem Cell Institute and Department of Stem Cell and Regenerative Biology, Harvard University, Cambridge, MA 02138, USA.
\end{abstract}

Received: 3 December 2012 Accepted: 12 February 2013

Published: 15 February 2013

\section{References}

1. Ahmed TA, Hincke MT: Strategies for articular cartilage lesion repair and functional restoration. Tissue Eng 2010, 16(3):305-329.

2. Vinatier C, Bouffi C, Merceron C, Gordeladze J, Brondello JM, Jorgensen C, Weiss P, Guicheux J, Noel D: Cartilage tissue engineering: towards a biomaterial-assisted mesenchymal stem cell therapy. Curr Stem Cell Res Ther 2009, 4(4):318-329.

3. Bernstein BE, Kamal M, Lindblad-Toh K, Bekiranov S, Bailey DK, Huebert DJ, McMahon S, Karlsson EK, Kulbokas EJ 3rd, Gingeras TR, Schreiber SL, Lander ES: Genomic maps and comparative analysis of histone modifications in human and mouse. Cell 2005, 120(2):169-181.

4. Mikkelsen TS, Ku M, Jaffe DB, Issac B, Lieberman E, Giannoukos G, Alvarez P, Brockman W, Kim TK, Koche RP, Lee W, Mendenhall E, O'Donovan A, Presser A, Russ C, Xie X, Meissner A, Wernig M, Jaenisch R, Nusbaum C, Lander ES, Bernstein BE: Genome-wide maps of chromatin state in pluripotent and lineage-committed cells. Nature 2007, 448(7153):553-560.

5. Hawkins RD, Hon GC, Lee LK, Ngo Q, Lister R, Pelizzola M, Edsall LE, Kuan $S_{,}$ Luu Y, Klugman S, Antosiewicz-Bourget J, Ye Z, Espinoza C, Agarwahl S, Shen L, Ruotti V, Wang W, Stewart R, Thomson JA, Ecker JR, Ren B: Distinct epigenomic landscapes of pluripotent and lineage-committed human cells. Cell Stem Cell 2010, 6(5):479-491.

6. Challen GA, Sun $D$, Jeong $M$, Luo M, Jelinek J, Berg JS, Bock C, Vasanthakumar A, Gu H, Xi Y, Liang S, Lu Y, Darlington GJ, Meissner A, Issa JP, Godley LA, Li W, Goodell MA: Dnmt3a is essential for hematopoietic stem cell differentiation. Nat Genet 2011, 44(1):23-31.

7. Guenther MG, Levine SS, Boyer LA, Jaenisch R, Young RA: A chromatin landmark and transcription initiation at most promoters in human cells. Cell 2007, 130(1):77-88

8. Bernstein BE, Mikkelsen TS, Xie X, Kamal M, Huebert DJ, Cuff J, Fry B, Meissner A, Wernig M, Plath K, Jaenisch R, Wagschal A, Feil R, Schreiber SL, Lander ES: A bivalent chromatin structure marks key developmental genes in embryonic stem cells. Cell 2006, 125(2):315-326.

9. Suganuma T, Workman JL: Signals and combinatorial functions of histone modifications. Annu Rev Biochem 2011, 80:473-499.

10. Mikkelsen TS, Xu Z, Zhang X, Wang L, Gimble JM, Lander ES, Rosen ED: Comparative epigenomic analysis of murine and human adipogenesis. Cell 2010, 143(1):156-169

11. Sorensen AL, Jacobsen BM, Reiner AH, Andersen IS, Collas P: Promoter DNA methylation patterns of differentiated cells are largely programmed at the progenitor stage. Mol Biol Cell 2010, 21(12):2066-2077.

12. Asp P. Blum R, Vethantham V, Parisi F, Micsinai M, Cheng J, Bowman C, Kluger $Y$, Dynlacht BD: Genome-wide remodeling of the epigenetic landscape during myogenic differentiation. Proc Natl Acad Sci USA 2011, 108(22):E149-158.

13. Lien WH, Guo X, Polak L, Lawton LN, Young RA, Zheng D, Fuchs E: Genome-wide maps of histone modifications unwind in vivo chromatin states of the hair follicle lineage. Cell Stem Cell 2011, 9(3):219-232.

14. Cedar H, Bergman Y: Epigenetics of haematopoietic cell development Nat Rev Immunol 2011, 11(7):478-488

15. Cui K, Zang C, Roh TY, Schones DE, Childs RW, Peng W, Zhao K: Chromatin signatures in multipotent human hematopoietic stem cells indicate the fate of bivalent genes during differentiation. Cell Stem Cell 2009, 4(1):80-93.

16. Hodges E, Molaro A, Dos Santos CO, Thekkat P, Song Q, Uren PJ, Park J, Butler J, Rafii S, McCombie WR, Smith AD, Hannon GJ: Directional DNA methylation changes and complex intermediate states accompany lineage specificity in the adult hematopoietic compartment. Mol Cell 2011, 44(1):17-28

17. Ezura Y, Sekiya I, Koga H, Muneta T, Noda M: Methylation status of CpG islands in the promoter regions of signature genes during chondrogenesis of human synovium-derived mesenchymal stem cells. Arthritis Rheum 2009, 60(5):1416-1426.

18. Furumatsu T, Asahara $\mathrm{H}$ : Histone acetylation influences the activity of Sox9-related transcriptional complex. Acta Med Okayama 2011, 64(6):351-357.

19. Zimmermann P, Boeuf S, Dickhut A, Boehmer S, Olek S, Richter W: Correlation of COL10A1 induction during chondrogenesis of mesenchymal stem cells with demethylation of two CpG sites in the COL10A1 promoter. Arthritis Rheum 2008, 58(9):2743-2753.

20. Goldring MB, Tsuchimochi K, ljiri K: The control of chondrogenesis. J Cell Biochem 2006, 97(1):33-44

21. Ichinose S, Yamagata K, Sekiya I, Muneta T, Tagami M: Detailed examination of cartilage formation and endochondral ossification using human mesenchymal stem cells. Clin Exp Pharmacol Physiol 2005, 32(7):561-570

22. Lefebvre V, Smits P: Transcriptional control of chondrocyte fate and differentiation. Birth Defects Res C Embryo Today 2005, 75(3):200-212.

23. Lefebvre V, Behringer RR, de Crombrugghe B: L-Sox5, Sox6 and Sox9 control essential steps of the chondrocyte differentiation pathway. Osteoarthritis and cartilage / OARS, Osteoarthritis Research Society 2001, 9(Suppl A):S69-75

24. Smits P, Li P, Mandel J, Zhang Z, Deng JM, Behringer RR, de Crombrugghe $B$, Lefebvre $V$ : The transcription factors L-Sox 5 and Sox6 are essential for cartilage formation. Dev Cell 2001, 1(2):277-290.

25. Ikeda T, Zhang J, Chano T, Mabuchi A, Fukuda A, Kawaguchi H, Nakamura K, Ikegawa S: Identification and characterization of the human long form of Sox5 (L-SOX5) gene. Gene 2002, 298(1):59-68.

26. Herlofsen SR, Kuchler AM, Melvik JE, Brinchmann JE: Chondrogenic differentiation of human bone marrow-derived mesenchymal stem cells in self-gelling alginate discs reveals novel chondrogenic signature gene clusters. Tissue Eng Part A 2011, 17(7-8):1003-1013.

27. Heintzman ND, Hon GC, Hawkins RD, Kheradpour P, Stark A, Harp LF, Ye Z Lee LK, Stuart RK, Ching CW, Ching KA, Antosiewicz-Bourget JE, Liu H, Zhang X, Green RD, Lobanenkov W, Stewart R, Thomson JA, Crawford GE, Kellis $M$, Ren B: Histone modifications at human enhancers reflect global cell-type-specific gene expression. Nature 2009, 459(7243):108-112.

28. Heintzman ND, Stuart RK, Hon G, Fu Y, Ching CW, Hawkins RD, Barrera LO, Van Calcar S, Qu C, Ching KA, Wang W, Weng Z, Green RD, Crawford GE, Ren B: Distinct and predictive chromatin signatures of transcriptional promoters and enhancers in the human genome. Nat Genet 2007, 39(3):311-318.

29. Tew SR, Clegg PD, Brew CJ, Redmond CM, Hardingham TE: SOX9 transduction of a human chondrocytic cell line identifies novel genes regulated in primary human chondrocytes and in osteoarthritis. Arthritis Res Ther 2007, 9(5):R107.

30. Kerney R, Hall BK, Hanken J: Regulatory elements of Xenopus col2a1 drive cartilaginous gene expression in transgenic frogs. Int J Dev Biol 2010, 54(1):141-150

31. Lefebvre V, Huang W, Harley VR, Goodfellow PN, de Crombrugghe B: SOX9 is a potent activator of the chondrocyte-specific enhancer of the pro alpha1(II) collagen gene. Mol Cell Biol 1997, 17(4):2336-2346.

32. Oh CD, Maity SN, Lu JF, Zhang J, Liang S, Coustry F, de Crombrugghe B, Yasuda $\mathrm{H}$ : Identification of SOX9 interaction sites in the genome of chondrocytes. PLoS One 2010, 5(4):e10113.

33. Zhou G, Lefebvre V, Zhang Z, Eberspaecher H, de Crombrugghe B: Three high mobility group-like sequences within a 48-base pair enhancer of the Col2a1 gene are required for cartilage-specific expression in vivo. $J$ Biol Chem 1998, 273(24):14989-14997.

34. Park JS, Yang HN, Woo DG, Jeon SY, Do HJ, Lim HY, Kim JH, Park KH: Chondrogenesis of human mesenchymal stem cells mediated by the combination of SOX trio SOX5, 6, and 9 genes complexed with PEImodified PLGA nanoparticles. Biomaterials 2011, 32(14):3679-3688.

35. Amarilio R, Viukov SV, Sharir A, Eshkar-Oren I, Johnson RS, Zelzer E: HIF1alpha regulation of Sox9 is necessary to maintain differentiation of hypoxic prechondrogenic cells during early skeletogenesis. Development 2007, 134(21):3917-3928

36. Greenwel P, Inagaki Y, Hu W, Walsh M, Ramirez F: Sp1 is required for the early response of alpha2(I) collagen to transforming growth factor-beta1. J Biol Chem 1997, 272(32):19738-19745. 
37. Iwamoto $\mathrm{M}$, Higuchi $\mathrm{Y}$, Enomoto-Iwamoto M, Kurisu K, Koyama E, Yeh $\mathrm{H}$, Rosenbloom J, Pacifici M: The role of ERG (ets related gene) in cartilage development. Osteoarthritis and cartilage / OARS, Osteoarthritis Research Society 2001, 9(Suppl A):S41-47.

38. Nakada C, lida A, Tabata Y, Watanabe S: Forkhead transcription factor foxe1 regulates chondrogenesis in zebrafish. J Exp Zool 2009, 312(8):827-840.

39. Boquest AC, Shahdadfar A, Fronsdal K, Sigurjonsson O, Tunheim SH, Collas $P$, Brinchmann JE: Isolation and transcription profiling of purified uncultured human stromal stem cells: alteration of gene expression after in vitro cell culture. Mol Biol Cell 2005, 16(3):1131-1141.

40. Nombela-Arrieta C, Ritz J, Silberstein LE: The elusive nature and function of mesenchymal stem cells. Nature reviews 2011, 12(2):126-131.

41. Weake VM, Workman JL: Inducible gene expression: diverse regulatory mechanisms. Nat Rev Genet 2010, 11(6):426-437.

42. Lindeman LC, Andersen IS, Reiner AH, Li N, Aanes H, Ostrup O, Winata C, Mathavan S, Muller F, Alestrom P, Collas P: Prepatterning of developmental gene expression by modified histones before zygotic genome activation. Dev Cell 2011, 21(6):993-1004.

43. Schuettengruber B, Chourrout D, Vervoort M, Leblanc B, Cavalli G: Genome regulation by polycomb and trithorax proteins. Cell 2007, 128(4):735-745.

44. Pirngruber J, Shchebet A, Johnsen SA: Insights into the function of the human P-TEFb component CDK9 in the regulation of chromatin modifications and co-transcriptional mRNA processing. Cell cycle (Georgetown, Tex) 2009, 8(22):3636-3642.

45. Vermeulen M, Mulder KW, Denissov S, Pijnappel WW, van Schaik FM, Varier RA, Baltissen MP, Stunnenberg HG, Mann M, Timmers HT: Selective anchoring of TFIID to nucleosomes by trimethylation of histone $\mathrm{H} 3$ lysine 4. Cell 2007, 131(1):58-69.

46. Vermeulen M, Eberl HC, Matarese F, Marks H, Denissov S, Butter F, Lee KK, Olsen JV, Hyman AA, Stunnenberg HG, Mann M: Quantitative interaction proteomics and genome-wide profiling of epigenetic histone marks and their readers. Cell 2010, 142(6):967-980.

47. Yun M, Wu J, Workman JL, Li B: Readers of histone modifications. Cell Res 2011, 21(4):564-578.

48. Yoh SM, Lucas JS, Jones KA: The Iws1:Spt6:CTD complex controls cotranscriptional mRNA biosynthesis and HYPB/Setd2-mediated histone H3K36 methylation. Genes Dev 2008, 22(24):3422-3434

49. Dysvik B, Jonassen I: J-Express: exploring gene expression data using Java. Bioinformatics (Oxford, England) 2001, 17(4):369-370.

50. Kolasinska-Zwierz P, Down T, Latorre I, Liu T, Liu XS, Ahringer J: Differential chromatin marking of introns and expressed exons by H3K36me3. Nat Genet 2009, 41(3):376-381.

51. Gu H, Bock C, Mikkelsen TS, Jager N, Smith ZD, Tomazou E, Gnirke A, Lander ES, Meissner A: Genome-scale DNA methylation mapping of clinical samples at single-nucleotide resolution. Nat Methods 2010, 7(2):133-136.

52. Murdoch AD, Grady LM, Ablett MP, Katopodi T, Meadows RS, Hardingham TE: Chondrogenic differentiation of human bone marrow stem cells in transwell cultures: generation of scaffold-free cartilage. Stem Cells 2007, 25(11):2786-2796.

doi:10.1186/1471-2164-14-105

Cite this article as: Herlofsen et al:: Genome-wide map of quantified epigenetic changes during in vitro chondrogenic differentiation of primary human mesenchymal stem cells. BMC Genomics 2013 14:105.

\section{Submit your next manuscript to BioMed Central and take full advantage of:}

- Convenient online submission

- Thorough peer review

- No space constraints or color figure charges

- Immediate publication on acceptance

- Inclusion in PubMed, CAS, Scopus and Google Scholar

- Research which is freely available for redistribution

Submit your manuscript at www.biomedcentral.com/submit
C Biomed Central 